\title{
Malignant Hepatic Epithelioid Hemangioendothelioma with Abdominal Pain due to Rapid Progression
}

\author{
Jun-ichiro Harada ${ }^{1}$, Hiroshi Yoshida ${ }^{1,2}$, Junji Ueda ${ }^{1}$, Yasuhiro Mamada ${ }^{1}$, \\ Nobuhiko Taniai ${ }^{1}$, Sho Mineta ${ }^{1}$, Masato Yoshioka ${ }^{1}$, Youichi Kawano', \\ Yoshinobu Shioda $^{3}$ and Eiji Uchida ${ }^{1}$ \\ ${ }^{1}$ Surgery for Organ Function and Biological Regulation, Graduate School of Medicine, Nippon Medical School \\ ${ }^{2}$ Department of Surgery, Nippon Medical School Tama Nagayama Hospital \\ ${ }^{3}$ Shioda Hospital, Chiba
}

\begin{abstract}
Hepatic epithelioid hemangioendothelioma (HEH) is a rare tumor. We report on a patient who underwent hepatectomy for malignant HEH associated with abdominal pain due to rapid progression. An 83-year-old man was admitted to Nippon Medical School Hospital because of acute, severe upper abdominal pain. Seven months before admission, a hepatic tumor, $3 \mathrm{~cm}$ in diameter, had been detected in the left lateral sector. The diagnosis was hepatic cavernous hemangioma. Abdominal ultrasonography revealed a heterogeneous hyperechoic tumor with a smooth border, $6 \mathrm{~cm}$ in diameter, in the left lateral sector (segment 3). Contrast-enhanced computed tomography of the abdomen showed that the tumor was enhanced from the early to the late phase. Abdominal angiography revealed a cotton wool-like appearance of the tumor. The diagnosis was hepatic cavernous hemangioma. A malignancy could not be ruled out because of the tumor's rapid growth, which had caused abdominal pain. Left hepatectomy was performed. Histopathological examination showed necrosis throughout the tumor. Slightly pleomorphic neoplastic cells with rounded, spindle-like nuclei and scant cytoplasm were sporadically found in vascular channels. Intracytoplasmic lumina occasionally contained red cells. Neoplastic cells were positive for factor VIII-related antigen, CD31, and CD34. The Mib-1 index was high. The tumor was diagnosed as malignant HEH. The postsurgical course was uneventful, and the patient was discharged on postoperative day 11. After 3 months, multiple metastatic tumors appeared in right hepatic lobe. Transcatheter arterial chemoembolization was performed.
\end{abstract}

(J Nippon Med Sch 2011; 78: 246-251)

Key words: epithelioid hemangioendothelioma, liver resection, recurrence

Correspondence to Jun-ichiro Harada, Department of Surgery, Nippon Medical School, 1-1-5 Sendagi, Bunkyo-ku, Tokyo 113-8603, Japan

E-mail: junji0821@nms.ac.jp

Journal Website (http://www.nms.ac.jp/jnms/) 


\section{Introduction}

Epithelioid hemangioendothelioma, first reported by Weiss and Enzinger in $1982^{1}$, is a rare borderline tumor composed of epithelioid, endothelial, or dendritic cells ${ }^{2}$. Its estimated prevalence is 1 per $1,000,000$ in the general population ${ }^{3}$. Epithelioid hemangioendothelioma is not specific to soft tissue and has occurred in other organs, such as the lung ${ }^{4-6}$, liver $^{2,7-11}$, bone ${ }^{12,13}$, brain ${ }^{14,15}$, heart ${ }^{16}$, salivary gland ${ }^{17}$, veins $^{18,19}$, and pleura ${ }^{20}$. Hepatic epithelioid hemangioendothelioma $(\mathrm{HEH})$ is a rare tumor that

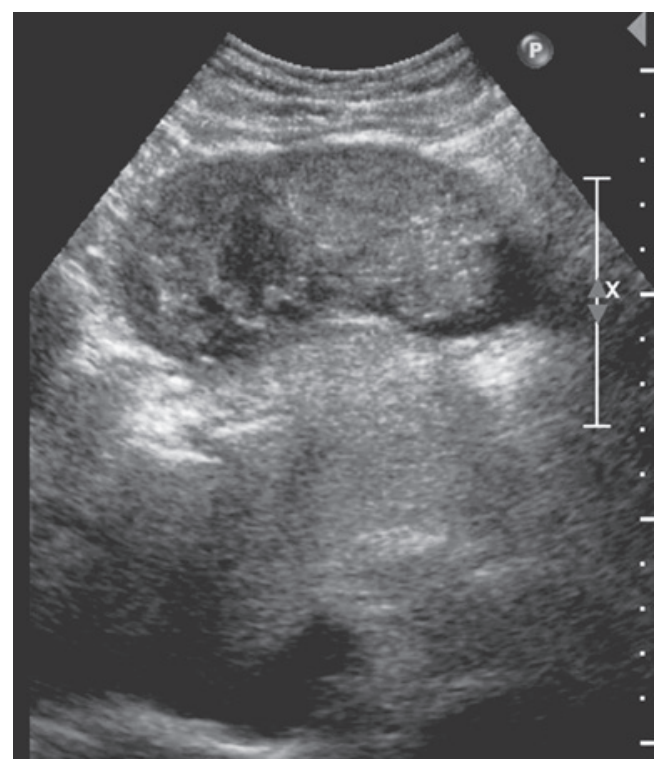

Fig. 1 An abdominal ultrasonographic image, showing an nonhomogeneous tumor with a smooth border in the left hepatic lobe (segment 3). The tumor was $6.0 \mathrm{~cm}$ in diameter. was first described by Ishak et al. in $1984^{2}$. The most common symptoms of $\mathrm{HEH}$ are upper abdominal pain and weight loss, but in most patients $\mathrm{HEH}$ is asymptomatic and found incidentally.

We report on a patient who underwent hepatectomy for malignant $\mathrm{HEH}$ associated with abdominal pain due to rapid progression.

\section{Case Report}

An 83-year-old man was admitted to Nippon Medical School Hospital because of acute, severe upper abdominal pain. Seven months before admission, a hepatic tumor, $3 \mathrm{~cm}$ in diameter, had been detected in the left lateral sector. The diagnosis was hepatic cavernous hemangioma. The medical history was not relevant to the present disorder. Initial laboratory tests revealed a serum hemoglobin concentration of $11.7 \mathrm{~g} / \mathrm{dL}$ (normal, 14 to $17 \mathrm{~g} / \mathrm{dL}$ ) and a serum platelet count of $10.4 \times 10^{4} / \mu \mathrm{L}$ (normal, 12 to $38 \times 10^{4} / \mu \mathrm{L}$ ). The serum concentration of carcinoembryonic antigen was 0.6 $\mathrm{ng} / \mathrm{mL}$ (normal, $<2.5 \mathrm{ng} / \mathrm{mL}$ ), that of PIVKA-2 was $18 \mathrm{mAU} / \mathrm{mL}$ (normal, $<37 \mathrm{mAU} / \mathrm{mL}$ ), and that of alpha-fetoprotein was $45.9 \mathrm{ng} / \mathrm{mL}$ (normal, <10 ng/ $\mathrm{mL}$ ). Serum surface antigens for hepatitis B and antihepatitis $\mathrm{C}$ virus antibodies were negative.

Abdominal ultrasonography revealed a heterogeneous hyperechoic tumor with a smooth border, $6 \mathrm{~cm}$ in diameter, in the left lateral sector (Segment 3) (Fig. 1). Contrast-enhanced computed tomography of the abdomen showed that the tumor was enhanced from the early to the late phase (Fig.
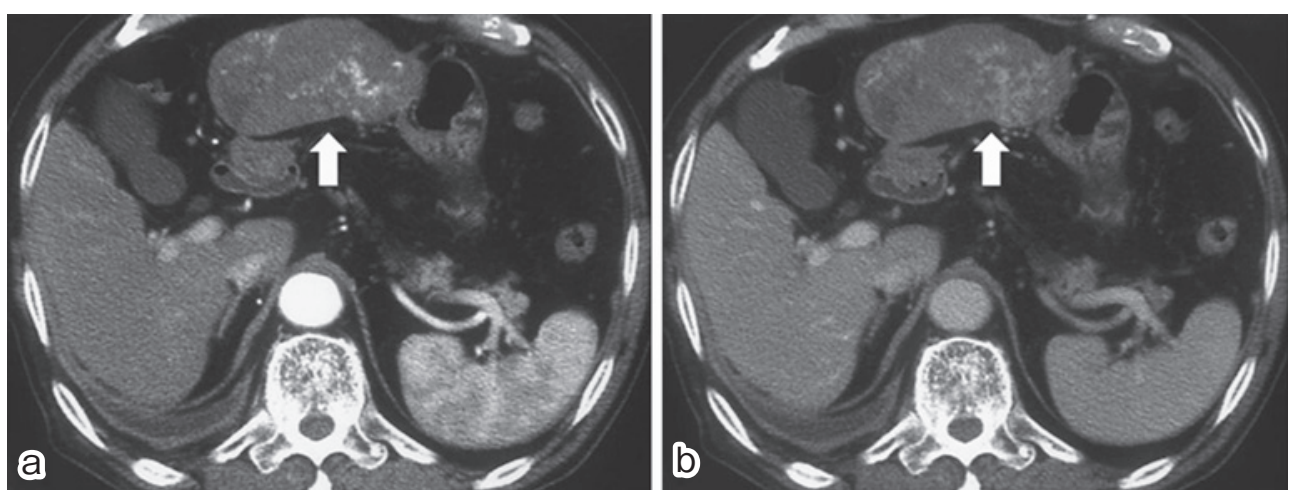

Fig. 2 A contrast-enhanced computed tomographic scan of the abdomen, showing that the tumor was enhanced from the early phase (a: arrow) to the late phase (b: arrow). 


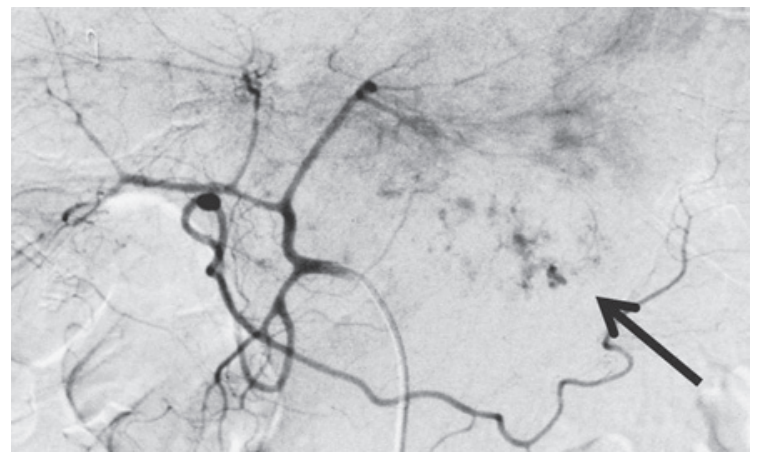

Fig. 3 An abdominal angiogram, showing a cotton wool-like appearance of the tumor (arrow).

2). Abdominal angiography revealed a cotton woollike appearance in the tumor (Fig. 3). The tumor was diagnosed to be a hepatic cavernous hemangioma. The malignant nature of the tumor could not be ruled out because it grew rapidly, causing abdominal pain. The patient underwent left hepatectomy. Histopathological examination showed necrosis throughout the tumor. Slightly pleomorphic neoplastic cells with rounded, spindle-like nuclei and scant cytoplasm were sporadically found in vascular channels. Intracytoplasmic lumina occasionally contained red cells. Neoplastic cells were positive for factor VIII-related antigen, CD31, and CD34. The Mib-1 index was high (Fig. 4). The tumor was diagnosed as malignant HEH. The postsurgical course was uneventful, and the patient was discharged on postoperative day 11. After 3 months, multiple metastatic tumors appeared in the right hepatic lobe. Transcatheter arterial chemoembolization was performed.

\section{Discussion}

HEH is a rare vascular tumor often mistaken for a carcinoma. The prevalence of HEH is unclear? $\mathrm{HEH}$ has been associated with oral contraceptives ${ }^{21}$, vinyl chloride ${ }^{22}$, polyurethane/silicone ${ }^{23}$, the contrast agent Thorotrast $\mathrm{t}^{24}$, primary biliary cirrhosis ${ }^{25}$, and hepatitis $B$ virus, but the etiology of HEH remains uncertain ${ }^{10}$. Although primary hepatic HEH is considered a lowgrade malignant neoplasm, its clinical course is highly unpredictable: some patients die within weeks after diagnosis, whereas others survive for prolonged periods despiteno active treatment ${ }^{26}$.
HEH is usually detected incidentally and is asymptomatic in $22 \%$ to $25 \%$ of patients. The most frequent clinical manifestations are nonspecific and include abdominal pain, weight loss, epigastric mass, ascites, nausea, jaundice, liver failure, Budd-Chiari syndrome, and portal hypertension ${ }^{6}$. At the time of diagnosis, most patients (87\%) have bilobar disease, and extrahepatic involvement is frequent (36.6\%). Our patient had acute severe upper abdominal pain due to rapid progression of the tumor, but only the left lobe was involved.

Imaging studies play an important role in the diagnosis of HEH. On ultrasonography, a hypoechoic pattern is found in the majority of cases (66.3\%). A heterogeneous pattern accounts is present in $22.5 \%$ of HEHs, whereas a hyperechoic and isoechoic pattern with a hypoechoic rim is rare $^{7}$. On noncontrast-enhanced computed tomography, hepatic HEHs appear as solid, nonhomogenously hypodense nodules with a ring-like, low-density border and a lower-density center. After administration of a contrast agent, the lesions show no enhancement or slight peripheral enhancement during the arterial phase, but a halo sign appears during the portal venous phase. A "capsular retraction" sign can occur near the lesions. Magnetic resonance imaging shows nonhomogenously hypointense lesions on T1weighted images and nonhomogenously hyperintense lesions on T2-weighted images. Lesions show peripheral ring-like enhancement during the arterial phase and stronger enhancement during the portal venous phase, with some lesions having a "halo" sign ${ }^{9}$. In our patient, abdominal ultrasonography revealed a heterogenously hyperechoic tumor with a smooth border. On contrast-enhanced computed tomography the tumor was enhanced from the early to the late phase. Abdominal angiography revealed a cotton wool-like appearance of the tumor. The tumor was diagnosed to be a hepatic cavernous hemangioma. A malignant nature could not be ruled out because the tumor grew rapidly, causing abdominal pain.

The diagnosis of HEH must be confirmed through microscopic examination of tissue ${ }^{8}$. Typical early histopathological features of HEH include an infiltrative growth pattern with preservation of the 


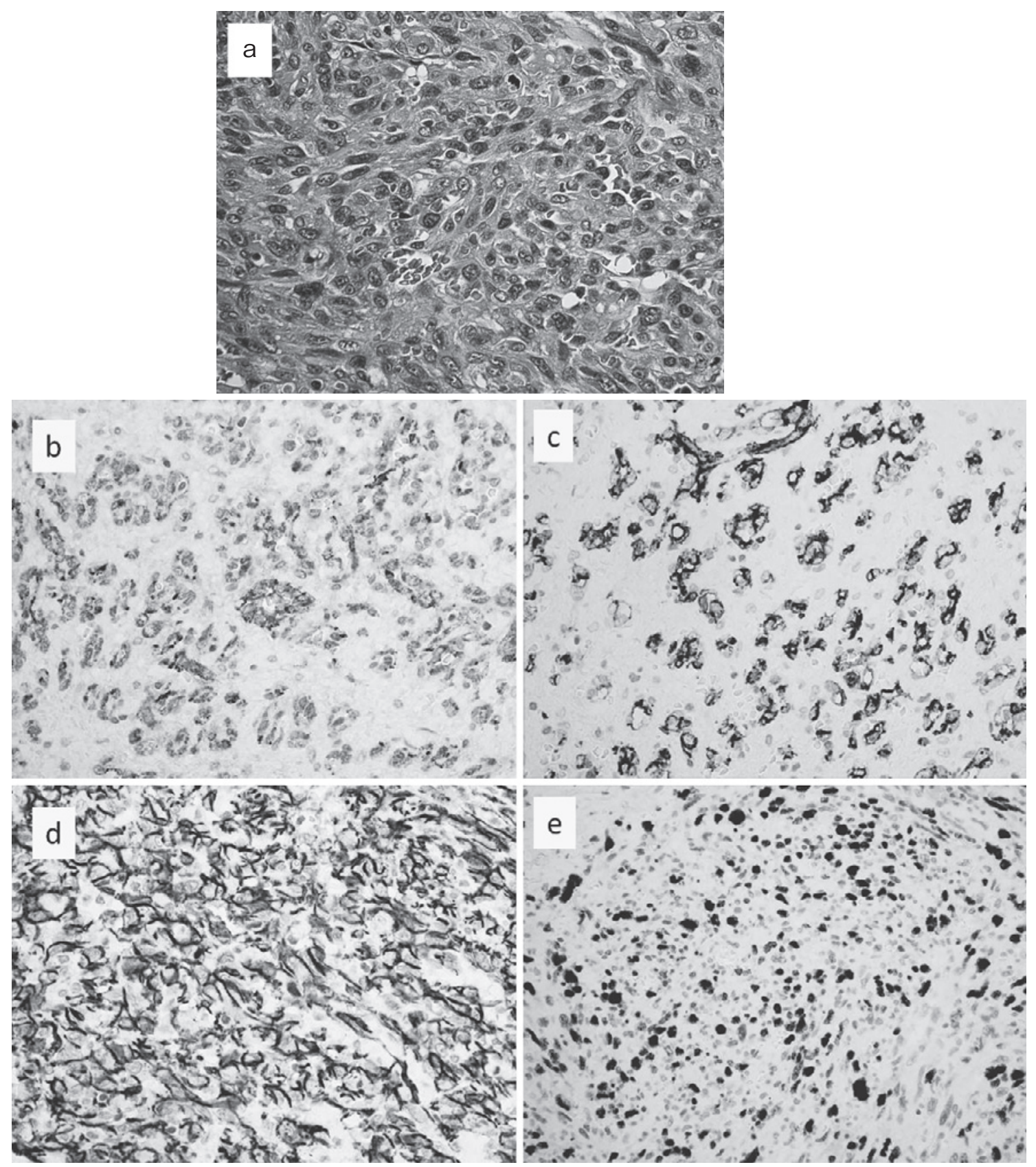

Fig. 4 Histopathological examination showed necrosis throughout the tumor. Slightly pleomorphic neoplastic cells with rounded, spindle-like nuclei and scant cytoplasm were sporadically found in vascular channels. Intracytoplasmic lumina occasionally contained red cells (hematoxylin and eosin, $\times 600$ ) (a). Neoplastic cells were positive for factor VIII-related antigen $(\times 600)(b)$, CD31 $(\times 600)$, and $(c)$, CD34 $(\times$ 600) (d). The Mib-1 index was high $(\times 400)(e)$.

liver acinar architecture and portal tracts. The tumor is composed of epithelioid, dendritic, or intermediate cells in a fibromyxoid stroma. The epithelioid cells are characterized by abundant eosinophilic cytoplasm and vesicular nuclei. Intracytoplasmic lumina, occasionally containing red cells, are common. The center of the tumor becomes sclerotic with neoplastic cells entrapped within regions of increased fibrosis. At the periphery, the tumor cells tend to infiltrate pre-existing sinusoids, terminal hepatic venules, and portal vein branches ${ }^{10}$. Endothelial differentiation was demonstrated by immunohistochemical staining for factor VIII-related antigen, CD34, and $\mathrm{CD}^{6} 1^{6}$. In the present case, immunohistochemical staining for endothelial cell markers, such as factor VIII-related antigen, CD34, 
and CD31, was consistently positive. In addition, the Mib-1 index exceeded 50\%. Malignant $\mathrm{HEH}$ was therefore diagnosed.

There is no standard treatment for $\mathrm{HEH}$, because of its rarity. Current treatments for $\mathrm{HEH}$ include liver transplantation (44.8\%), chemotherapy or radiotherapy (21\%), and liver resection (9.4\%); $24.8 \%$ of patients with $\mathrm{HEH}$ receive no treatment ${ }^{3}$. Resection for localized lesions, even extended hepatic lobectomy, is agenerally accepted procedure $^{27}$. For patients with no metastases, orthotopic liver transplantation may be justified as another potentially curative procedure ${ }^{28}$. Tumor resection is possible in only a limited number of cases because most HEHs are multiple and nodular or diffuse. In recent years, most cases have been treated with liver transplantation ${ }^{29,30}$. However, some patients have had rapid tumor recurrence in liver grafts after transplantation ${ }^{31,32}$. In our patient, the tumor was solitary and had not metastasized outside the liver. However, postoperative chemotherapy with such drugs as doxorubicin and 5-fluorouracil has been recommended for patients with extrahepatic disease ${ }^{33}$. We performed left hepatectomy, but after only 3 months, multiple metastatic tumors appeared in the right hepatic lobe, and transcatheter arterial chemoembolization was performed. The 5-year survival rates of patients who undergo liver resection $(75 \%)$ or transplantation $(54.8 \%-75 \%)$ are significantly higher than those of patients who received other treatments $(30 \%)$. The 5 -year survival rate of patients given no treatment was only $4.5 \%$ after a mean follow-up of 26 months $^{3,33}$. Drugs such as interferon have been used in combination with hepatic resection or transplantation in some patients and have successfully prevented or reduced the rate of metastasis ${ }^{23,34,35}$.

The clinical outcomes of HEH are unpredictable ${ }^{26}$. The prognosis of $\mathrm{HEH}$ ranges from favorable with prolonged survival, even without therapy, to rapid progression with a fatal outcome ${ }^{11}$. In patients who have received no treatment or have undergone orthotopic liver transplantation with positive lymphnodes or vascular invasion ${ }^{2,26,36-38}$, long-term survival and even spontaneous regression of the lesions have been reported ${ }^{26,39}$. In contrast, the tumor may rapidly progress, leading to liver failure and death $^{40}$. The prognosis of EHE usually is much more favorable than that of angiosarcoma; prolonged survival (5-28 years) has been reported after surgical resection or liver transplantation. Makhlouf et al have reported that in a series of 60 patients with $\mathrm{HEH}$, the rate of metastasis was $27 \%$. Survival ranged from 4 months to 28 years; $43 \%$ of their patients (26 of 60 patients) survived for more than 5 years $^{26}$. Due to the rarity and the unpredictable course of HEH, early diagnosis and curative therapy are imperative. In conclusion, malignant $\mathrm{HEH}$ should be suspected when a hepatic tumor resembling a cavernous hemangioma progresses rapidly.

\section{References}

1. Weiss SW, Enzinger FM: Epithelioid hemangioendothelioma: a vascular tumor often mistaken for a carcinoma. Cancer 1982; 50: 970-981.

2. Ishak KG, Sesterhenn IA, Goodman ZD, Rabin L, Stromeyer FW: Epithelioid hemangioendothelioma of the liver: a clinicopathologic and follow-up study of 32 cases. Hum Pathol 1984; 15: 839-852.

3. Mehrabi A, Kashfi A, Fonouni H, et al: Primary malignant hepatic epithelioid hemangioendothelioma: a comprehensive review of the literature with emphasis on the surgical therapy. Cancer 2006; 107: 2108-2121.

4. Bagan P, Hassan M, Le Pimpec Barthes F, et al:: Prognostic factors and surgical indications of pulmonary epithelioid hemangioendothelioma: a review of the literature. Ann Thorac Surg 2006; 82: 2010-2013.

5. Schattenberg T, Kam R, Klopp M, et al.: Pulmonary epithelioid hemangioendothelioma: report of three cases. Surg Today 2008; 38: 844-849.

6. Caruso S, Miraglia R, Maruzzelli L, et al.: An unusual presentation of malignant hepatic epithelioid haemangioendothelioma with left pleural and pulmonary localization. Pediatr Radiol 2008; 38: 10271030.

7. Ji ZF, Shen XZ, Zhang DY, et al.: Hepatic epithelioid hemangioendothelioma: a report of six patients. J Dig Dis 2010; 11: 254-258.

8. Hsieh MS, Liang PC, Kao YC, Shun CT: Hepatic epithelioid hemangioendothelioma in Taiwan: a clinicopathologic study of six cases in a single institution over a 15-year period. J Formos Med Assoc 2010; 109: 219-227.

9. Lin J, Ji Y: CT and MRI diagnosis of hepatic epithelioid hemangioendothelioma. Hepatobiliary Pancreat Dis Int 2010; 9: 154-158.

10. Thin LW, Wong DD, De Boer BW, et al: Hepatic epithelioid haemangioendothelioma: challenges in diagnosis and management. Intern Med J 2010; 40: 
710-715.

11. Mosoia L, Mabrut JY, Adham M, et al.: Hepatic epithelioid hemangioendothelioma: long-term results of surgical management. J Surg Oncol 2008; 98: 432437.

12. Ellis TS, Schwartz A, Starr JK, Riedel CJ: Epithelioid hemangioendothelioma of the lumbar vertebral column: case report and review of literature. Neurosurgery 1996; 38: 402-407.

13. Kopniczky Z, Tsimpas A, Lawson DD, et al: Epithelioid hemangioendothelioma of the spine: report of two cases and review of the literature. $\mathrm{Br} \mathrm{J}$ Neurosurg 2008; 22: 793-797.

14. Endo T, Su CC, Numagami Y, Shirane R: Malignant intracranial epithelioid hemangioendothelioma presumably originating from the lung: case report. J Neurooncol 2004; 67: 337-343.

15. Parajon A, Vaquero J: Meningel intracranial epithelioid hemangioendothelioma: case report and literature review. J Neurooncol 2008; 88: 169-173.

16. Val-Bernal JF, Garcia-Alberdi E, Gutierrez JA, Garijo MF: Incidental in vivo detection of an epithelioid hemangioendothelioma of the mitral valve. Pathol Int 2005; 55: 644-648.

17. Pigadas N, Mohamid W, McDermott P: Epithelioid hemangioendothelioma of the parotid salivary gland. Oral Surg Oral Med Oral Pathol Oral Radiol Endod 2000; 89: 730-738.

18. Ferretti GR, Chiles C, Woodruff RD, Choplin RH: Epithelioid hemangioendothelioma of the superior vena cava: computed tomography demonstration and review of the literature. J Thorac Imaging 1998; 13: $45-48$.

19. Charette S, Nehler MR, Whitehill TA, Gibbs P, Foulk D, Krupski WC: Epithelioid hemangioendothelioma of the common femoral vein: Case report and review of the literature. J Vasc Surg 2001; 33: 1100-1103.

20. Lee YJ, Chung MJ, Jeong KC, et al.: Pleural epithelioid hemangioendothelioma. Yonsei Med J 2008; 49: 1036-1040.

21. Dean PJ, Haggitt RC, O’Hara CJ: Malignant epithelioid hemangioendothelioma of the liver in young women. Relationship to oral contraceptive use. Am J Surg Pathol 1985; 9: 695-704.

22. Gelin M, Van de Stadt J, Rickaert F, et al.: Epithelioid hemangioendothelioma of the liver following contact with vinyl chloride. Recurrence after orthotopic liver transplantation. J Hepatol 1989; 8: 99-106.

23. Marsh Rde W, Walker MH, Jacob G, Liu C: Breast implants as a possible etiology of epithelioid hemangioendothelioma and successful therapy with interferon-alpha2. Breast J 2005; 11: 257-261.

24. Sakai K, Shiina M, Ishihara N, Kato Y: Thorotrastinduced multiple primary malignant tumors of the liver - cholangiocarcinoma and malignant hemangioendothelioma. Jpn J Clin Oncol 1984; 14: 411-416.

25. Terada T, Hoso M, Kono N, Watanabe K, Nakanuma Y: Epithelioid hemangioendothelioma of the liver in primary biliary cirrhosis. A case report. Acta Pathol Jpn 1989; 39: 607-611.

26. Makhlouf HR, Ishak KG, Goodman ZD: Epithelioid hemangioendothelioma of the liver : a clinicopathologic study of 137 cases. Cancer 1999; 85: 562-582.

27. Woodall CE, Scoggins CR, Lewis AM, McMasters KM, Martin RC: Hepatic malignant epithelioid hemangioendothelioma: a case report and review of the literature. Am Surg 2008; 74: 64-68.

28. Lauffer JM, Zimmermann A, Krahenbuhl L, Triller J, Baer HU: Epithelioid hemangioendothelioma of the liver. A rare hepatic tumor. Cancer 1996; 78: 23182327.

29. Lerut JP, Orlando G, Sempoux C, et al: Hepatic haemangioendothelioma in adults: excellent outcome following liver transplantation. Transpl Int 2004; 17: 202-207.

30. Demetris AJ, Minervini M, Raikow RB, Lee RG: Hepatic epithelioid hemangioendothelioma: biological questions based on pattern of recurrence in an allograft and tumor immunophenotype. Am J Surg Pathol 1997; 21: 263-270.

31. Ben-Haim M, Roayaie S, Ye MQ, et al.: Hepatic epithelioid hemangioendothelioma: resection or transplantation, which and when? Liver Transpl Surg 1999; 5: 526-531.

32. Kelleher MB, Iwatsuki S, Sheahan DG: Epithelioid hemangioendothelioma of liver. Clinicopathological correlation of 10 cases treated by orthotopic liver transplantation. Am J Surg Pathol 1989; 13: 999-1008.

33. Hertl M, Cosimi AB: Liver transplantation for malignancy. Oncologist 2005; 10: 269-281.

34. Kayler LK, Merion RM, Arenas JD, et al.: Epithelioid hemangioendothelioma of the liver disseminated to the peritoneum treated with liver transplantation and interferon alpha-2B. Transplantation 2002; 74: 128-130.

35. Galvao FH, Bakonyi-Neto A, Machado MA, et al.: Interferon alpha-2B and liver resection to treat multifocal hepatic epithelioid hemangioendothelioma: a relevant approach to avoid liver transplantation. Transplant Proc 2005; 37: 4354-4358.

36. Madariaga JR, Marino IR, Karavias DD, et al.: Longterm results after liver transplantation for primary hepatic epithelioid hemangioendothelioma. Ann Surg Oncol 1995; 2: 483-487.

37. Marino IR, Todo S, Tzakis AG, et al: Treatment of hepatic epithelioid hemangioendothelioma with liver transplantation. Cancer 1988; 62: 2079-2084.

38. Scoazec JY, Lamy P, Degott C, et al.: Epithelioid hemangioendotheliom of the liver. Diagnostic features and role of liver transplantation. Gastroenterology 1988; 94: 1447-1453.

39. Otrock ZK, Al-Kutoubi A, Kattar MM, et al.: Spontaneous complete regression of hepatic epithelioid haemangioendothelioma. Lancet Oncol 2006; 7: 439-441.

40. Mehrabi A, Kashfi A, Schemmer P, et al: Surgical treatment of primary hepatic epithelioid hemangioendothelioma. Transplantation 2005; 80: 109-112.

(Received, December 30, 2010)

(Accepted, March 10, 2011) 